\title{
Profile of Congenital Heart Disease in childhood
}

\author{
Hajela S \\ Dr. Shalini Hajela, Assistant Professor, Department of Pediatrics, Bundelkhand Medical College, Sagar, M P, India
}

Address for Correspondence: Dr Shalini Hajela, Email: shalinihajela@gmail.com

\begin{abstract}
Introduction: Globally, the prevalence of congenital heart diseases is 3.7 to 17.5 per 1000 live births; in India, it is 2.25 5.2 per 1000 children. The profile of Congenital Heart Disease varies with the age group; Simple heart defects are common at all ages, whereas serious defects are seen in autopsy. This study aims to assess the clinical profile of Congenital Heart Disease. Materials and Methods: The study was conducted in Department of Pediatrics, Bundelkhand Medical College, Sagar, India. It was a prospective study of cases attending the pediatric outpatient and inpatient department, as described by inclusion criteria over a period of 1 year. 100 cases could be included. Clinical assessment, 2 D Echocardiography and Color Doppler were used for diagnosis. Results: A prevalence of 15.38 per 1000 patients was observed. The commonest acyanotic Congenital Heart Disease was Ventricular septal defect (29\%), followed by Atrial septal defect (13\%) and Patent ductus arteriosus (5\%). The commonest Cyanotic Congenital Heart Disease was Tetralogy of Fallot (26\%) followed by Transposition of Great Arteries (9\%) and Total anomalous Pulmonary Venous Connection (4\%). Most children with heart disease were diagnosed between 1-5 years of age, acyanotic heart disease presenting at a mean age of 11.5 months, cyanotic heart disease with decreased pulmonary blood flow at 10.5 months and cyanotic heart disease with increased pulmonary blood flow at 5 months. Conclusions: Heart diseases are a significant cause of morbidity and mortality in children. Early diagnosis and early referral for definitive surgery is necessary to improve their quality of life.
\end{abstract}

Keywords: Childhood, Congenital heart disease, Profile

\section{Introduction}

The burden of congenital heart diseases (CHD) in India is likely to be enormous with high morbidity and mortality, due to a high birth rate [1]. The reported prevalence of congenital heart diseases (CHD) ranges from 1.01 to 17.5 per 1000 live births according to various studies over the world [2-4]. In India, the prevalence of CHD is 2.25-5.2 per 1000 children [5]. In India, the incidence of CHD is 3.9/1000 live births, as reported by a Khalil et al in a hospital based study [6]. In community based studies from India the prevalence of CHD ranges from $0.8-5.2 / 1000$ children $[5,7]$. Nearly $1 / 3^{\text {rd }}$ of the congenital heart diseases (CHD) are critical requiring interventions in the first year of life [8]. CHDs contribute to infant mortality significantly as $7 \%$ of the neonatal deaths are due to congenital malformations, $25 \%$ of which are cardiovascular [8]. In India, $10 \%$ of the present infant mortality may be accounted for by Congenital Heart Disease as reported by Saxena et al

Manuscript received: $10^{\text {th }}$ May 2014

Reviewed: $25^{\text {th }}$ May 2014

Author Corrected: $10^{\text {th }}$ June 2014

Accepted for Publication: $13^{\text {th }}$ June 2014
[9]. The profile of Congenital Heart Disease varies with the age group studied. Simple and potentially correctable heart defects like Ventricular Septal defect(VSD), Atrial Septal Defect (ASD) and patent ductus arteriosus(PDA) are common at all the ages. High prevalence of Hypoplastic Left Heart Syndrome like mitral atresia, aortic atresia and coarctation of aorta are seen in autopsy studies. The incidence of severe CHD requiring expert cardiologic care is quite stable at 2.5-3/1000 live births surgery [10].

CHDs can be classified into 3 groups of lesions considering severity, late complications and effects of surgery $[11,12]$

1. Severe Congenital Heart Disease is symptomatic in newborn or early infancy, viz.Cyanotic Heart Disease

Transposition of great arteries(TGA), Tetralogy of Fallot(TOF), Hypoplastic Right Heart \{ Tricuspid Atresia(TA) , Pulmonary Atresia(PA), Ebstein 
Anomaly\}, Hypoplastic Left Heart (Aortic Atresia, Mitral Atresia), Single Ventricle, Double Outlet Right Ventricle(DORV), Truncus Arteriosus, Total Anomalous Pulmonary Venous Connection(TAPVC), Critical Pulmonary Stenosis, uncommon lesions like Double inlet left ventricle(DILV), unusual malpositions. Acyanotic Heart Disease

Atrioventricular Septal Defects (AVSD), Large Ventricular Septal Defect (VSD), Large Patent Ductus Arteriosus(PDA), Critical or severe Pulmonary Stenosis(PS), Critical or severe Aortic Stenosis(AS), Critical Coarctation.

2. Moderate Congenital Heart Disease require expert care, but relatively less intensive as severe CHD, viz. Mild or Moderate Aortic Stenosis or incompetence, Moderate Pulmonary Stenosis or incompetence, noncritical coarctation, large Atrial Septal Defect(ASD), Complex Ventricular Septal defect.

3. Mild Congenital Heart Disease is mostly asymptomatic, most numerous and undergoes early spontaneous resolution, viz. small ventricular septal defect, small patent ductus arteriosus(PDA), mild pulmonary stenosis, bicuspid aortic valve, small or spontaneously closed atrial septal defect.
We conducted this study to assess the profile and problems of Congenital Heart Disease among patients attending a tertiary care government hospital in central India.

\section{Methods}

The study was conducted in Sagar over a period of 1 year from January 2012 to January 2013. The study was conducted in Pediatric Department, Bundelkhand Medical College, Sagar. An analysis of pediatric patients visiting OPD (outpatient department) and IPD (inpatient department) was done, ages from 0 - 15 years, during the abovementioned period, in patients fulfilling inclusion criteria, after written informed consent. 115 cases were recorded of which 100 cases could be included as decided by inclusion criteria. Children diagnosed with Congenital Heart Disease were analyzed further. Clinical Examination, 2 D Echocardiography and Color Doppler were considered as definitive tools for diagnosis of CHD. Lesions excluded were functionless abnormalities of great veins (persistent left superior vena cava), congenital arrythmias (Long QT syndrome, Wolf-Parkinson-White Syndrome), hypertrophic or dilated cardiomyopathy. Proportions were calculated for all observations and Z-test was applied for comparison between observations.

\section{Observations and Results}

A prevalence of 15.38 per 1000 patients was observed.

Table 1: Distribution of Heart Diseases in Children (category wise and severity wise)

\begin{tabular}{|l|l|l|l|l|l|}
\hline Classification & $\begin{array}{l}\text { Severe No } \\
(\mathbf{\%})\end{array}$ & $\begin{array}{l}\text { Moderate No } \\
(\mathbf{\%})\end{array}$ & Mild No (\%) & Total No (\%) & Sig. \\
\hline ACHD & $31(62 \%)$ & $15(30 \%)$ & $4(8 \%)$ & $50(100)$ & \\
\hline CCHD $<$ PBF & $29(100 \%)$ & $0(0)$ & $0(0)$ & $29(100)$ & P $<0.002$ \\
\hline CCHD $>$ PBF & $21(100 \%)$ & $0(0)$ & $0(0)$ & $21(100)$ & \\
\hline
\end{tabular}

Acyanotic congenital heart disease comprised 50 cases (50\%). Rest 50 cases $(50 \%)$ had cyanotic heart disease, cyanotic heart disease with decreased pulmonary blood flow in $29 \%$ and cyanotic heart disease with increased pulmonary blood flow in $21 \%$.

Table 2: Distribution of Acyanotic Congenital Heart Diseases

\begin{tabular}{|l|l|l|}
\hline ACHD & N & \% \\
\hline Ventricular Septal Defects & 29 & 58 \\
\hline Atrial Septal Defects & 13 & 26 \\
\hline Patent Ductus Arteriosus & 5 & 10 \\
\hline AtrioVentricularSeptal Defects & 1 & 2 \\
\hline Pulmonary Stenosis & 1 & 2 \\
\hline Aortic Stenosis & 1 & 2 \\
\hline
\end{tabular}


VSD was the most common heart lesion (29\%). Among the acyanotic lesions, ventricular septal defects were the maximum, 58\% followed by Atrial Septal defects, 26\%, Patent ductus Arteriosus, 10\%, Atrioventricular septal defects and other mixed lesions. Amongst VSDs, 20 cases were simple VSD, whereas 9 were mixed defects; Ventricular Septal Defect was associated with patent ductus arteriosus in 2, with Atrial Septal Defects in 2, with Pulmonary Stenosis in 2, with Pulmonary Vein Stenosis in 1, with Aortic Regurgitation in 1 and with patent ductus arteriosus with atrial septal defect in 1. Among VSDs, sub aortic VSD was the most common subtype (44.8\%), followed by muscular (31\%), perimembranous (13.7\%), subpulmonic (6.9\%) and inlet (3.4\%). Among ASDs, ostium secondum ASD was the most common subtype (61.5\%), followed by sinus venosus ASD (30.8\%) and os primum ASD (7.7\%).

Table 3: Distribution of Cyanotic Congenital Heart Diseases

\begin{tabular}{|l|l|l|}
\hline Cyanotic CHD & No & \% \\
\hline Tetralogy of Fallot & 26 & 52 \\
\hline Transposition of Great Arteries & 9 & 18 \\
\hline $\begin{array}{l}\text { Total Anomalous Pulmonary } \\
\text { Venous Connection }\end{array}$ & 4 & 8 \\
\hline Truncus Arteriosus & 2 & 4 \\
\hline Double Inlet Left Ventricle & 1 & 2 \\
\hline Double Outlet Right Ventricle & 3 & 6 \\
\hline Others & 5 & 10 \\
\hline
\end{tabular}

Most common cyanotic heart disease was Tetralogy of Fallot (26\%).Among cyanotic lesions; Tetralogy of Fallot was commonest $(52 \%)$ to be followed by transposition of great arteries (18\%), Total anomalous pulmonary venous connections (8\%) and others. Among TAPVCs, $40 \%$ were supracardiac, $40 \%$ were cardiac and $20 \%$ were infracardiac. Others include 1 case of Pulmonary Atresia with Hypoplastic Right Ventricle, 1 case of Ebstein Anomaly, 1 case of tricuspid atresia, 1 case of Transposition of Great Arteries (TGA) with Double Inlet Left Ventricle (DILV), one case of Double Outlet Right Ventricle with Dextrocardia with Patent Ductus Arteriosus.

Table 4: Agewise disease-wise distribution of Heart Diseases in Children

\begin{tabular}{|l|l|l|l|l|}
\hline \multirow{2}{*}{ Age } & ACHD & CCHD $<$ PBF & CCHD $>$ PBF & \\
\cline { 2 - 4 } & N0 (\%) & No $(\%)$ & No $(\%)$ & \\
\hline$<$ month & $0(0)$ & $0(0)$ & $5(100)$ \\
\hline 1month-1 year & $16(61.5)$ & $4(15.4)$ & $6(23.1)$ & \\
\hline 1-5 years & $24(50)$ & $16(33.3)$ & $7(14.6)$ & \\
\hline 5-10 years & $8(53.3)$ & $5(33.3)$ & $2(13.3)$ & \\
\hline 10-18 years & $2(28.5)$ & $4(57.1)$ & $1(14.2)$ & \\
\hline Total & $50(50)$ & $29(29)$ & $21(21)$ & \\
\hline
\end{tabular}

ACHD: Acyanotic congenital heart disease, CCHD: Cyanotic congenital heart disease, PBF: Pulmonary blood flow

The presentation below 1 month was observed in cyanotic congenital heart disease with increased pulmonary blood flow group. The maximum number of patients presenting in infancy (61.5\%), in 1-5 yr age group (50\%) and in 5-10 yr age group (53.3\%) were in acyanotic group. The cyanotic heart disease with decreased pulmonary blood flow accounted for $57.1 \%$ of cases in 10-15 year age group. The chi square test suggests a significant $p$-value $<0.05$ suggesting significant difference in presentation of different types of heart diseases in different age groups. Maximum numbers of cases were seen in $1-5$ years age group $(n=47,47 \%)$. The mean age of presentation was 11.5 months in ACHD group, 10.5 months in $\mathrm{CCHD}<\mathrm{PBF}$ group and 5 months in $\mathrm{CCHD}>\mathrm{PBF}$ group.

Females comprised $41 \%$ of the heart diseases while males comprised the remaining 59\%. There was female preponderance noted in VSDs, whereas TOF, TGA, ASD, showed male preponderance. Cyanosis was a significant distinguishing feature seen in cyanotic heart diseases, although 6\% ACHDs also showed transient cyanosis. Baseline cyanosis was seen in $62 \%$ of Cyanotic congenital Heart Disease with decreased pulmonary blood flow (CHD $<$ PBF) and in $68.4 \%$ of Cyanotic congenital Heart Disease with increased pulmonary blood flow (CCHD $>$ PBF). In $8 \%$ of the acyanotic 
heart diseases, dysmorphisms were noted. These include low set ears, depressed nasal bridge, polydactyly and ocular abnormalities.

Harrison's sulcus was seen in 48\%, diastolic shock in 50\%, parasternal heave in $58 \%$ and thrill in $52 \%$ of ACHDs. Height was low in $66 \%$ of ACHD patients, in $62 \%$ of the $\mathrm{CCHD}<\mathrm{PBF}$ patients and in $60 \%$ of $\mathrm{CCHD}>\mathrm{PBF}$ patients. This was similar in all the groups (p-value not significant 0.905 ). Weight was low in 90\% patients, $79.3 \%$ of $\mathrm{CCHD}<\mathrm{PBF}$ patients and $68 \%$ of $\mathrm{CCHD}>\mathrm{PBF}$. Head Circumference was low in $34 \%$ ACHD patients, in $31 \%$ $\mathrm{CCHD}<\mathrm{PBF}$ in patients and in $73.7 \% \mathrm{CCHD}>\mathrm{PBF}$ patients.

Developmental Quotient was lower than normal in $65 \%$ of $\mathrm{CCHD}<\mathrm{PBF}$ cases, $52.6 \%$ of $\mathrm{CCHD}>\mathrm{PBF}$ and in $36 \%$ of acyanotic CHDs, statistically significant (p-value- $<0.037)$.

In ACHDs pulsatile precordium was seen in $56 \%$, precordium was predominantly silent in $\mathrm{CCHD}<\mathrm{PBF}$ group, although 2 cases $(6.9 \%$ ) had pulsatile precordium; secondary to low weight and thin chest wall, $57.9 \%$ CCHD $>$ PBF had silent precordium and $42.1 \%$ had pulsatile precordium. $82 \%$ of patients in ACHD group had left ventricular hypertrophy, 96.6\% of $\mathrm{CCHD}<\mathrm{PBF}$ group patients had Right Ventricular Hypertrophy whereas $94.7 \%$ of CCHD $>$ PBF group patients had Right Ventricular Hypertrophy and 63.2\% had Left Ventricular Hypertrophy.

Lower respiratory Tract Infections were preponderant in CHDs especially Acyanotic CHDs, suffering an average of 2.2 episodes per year. Bonferroni's multiple comparison post hoc tests showed a significant difference in between acyanotic heart disease group against Cyanotic heart disease with decreased pulmonary blood $f$ low group ( $p$ value-0.001).

\section{Discussion}

Congenital heart diseases (CHD) burden in India is enormous, due to a high birth rate. CHDs contribute to infant mortality significantly as $7 \%$ of the neonatal deaths are due to congenital malformations, $25 \%$ of which are cardiovascular [10]. Our observation of prevalence of $15.38 / 1000$ patients cannot be compared to earlier studies, because we included all mild moderate and severe $\mathrm{CHD}$, in age group ranging from 0-15 years not particularly focusing on newborns or school children. One study in North India, in Kanpur [7], gives prevalence as 26.4/1000 patients, which was also a study on 0-15 years age group, although it was a retrospective analysis of records of CHD patients.

Table 5: Global Prevalence of Congenital Heart Disease per 1000 live births

\begin{tabular}{|c|c|c|}
\hline Country & Year & Frequency \\
\hline $\mathbf{U K}^{13}$ & 1981 & 5.51 \\
\hline $\mathbf{U S A}^{14}$ & 1990 & 6.6 \\
\hline Hong-Kong ${ }^{15}$ & 1991 & 6.35 \\
\hline Norway $^{16}$ & 1994 & 10.6 \\
\hline Pakistan $^{17}$ & 1997 & 4 \\
\hline Saudi $^{18}$ & 2001 & 10.7 \\
\hline Egypt $^{6}$ & 2000 & 1.01 \\
\hline South Africa ${ }^{19}$ & 1979 & 3.9 \\
\hline Spain $^{20}$ & 2005 & 8.96 \\
\hline India $^{8}$ & 1994 & 3.9 \\
\hline
\end{tabular}

This table represents the frequency of congenital heart disease per 1000 live births, as mentioned in various studies representing a range from 1.01 to 10.7 per 1000 live births, minimum reported in Egypt [6], and maximum in Saudi Arabia [18]. In India, the incidence of congenital heart disease for 1000 live births was observed as 3.9/1000 live births, by Khalil et al in their study on 10964 live births in a hospital based study[8]. 
Table 6: Prevalence of CHD in India

\begin{tabular}{|c|c|c|}
\hline Region & Year & Frequency \\
\hline North India $^{21}$ & 1962 & 31 \\
\hline South India $^{22}$ & 1968 & 25.6 \\
\hline Chandigarh $^{23}$ & 1971 & 50.8 \\
\hline $\mathbf{J} \& \mathbf{K}^{24}$ & 1979 & 9.7 \\
\hline New Delhi' ${ }^{25}$ & 1980 & 3.2 \\
\hline Agra $^{9}$ & 1993 & 5.2 \\
\hline New Delhi' ${ }^{26}$ & 1994 & 3.9 \\
\hline Shimla $^{27}$ & 1995 & 2.25 \\
\hline New Delhi' ${ }^{28}$ & 2001 & 4.2 \\
\hline
\end{tabular}

This Table presents the relative distribution of Congenital Heart Disease in various regions of India, ranging from 3.2 to 50.8 per 1000 live births, maximum reported in Chandigarh [23] and least in Shimla [27]. The average prevalence of Congenital Heart Disease in various regions of India is 14.7 per thousand live births. This amounts to the vast number of children with Congenital Heart Disease and the need for care in these children. Our study had the limitation that the CHD incidence could not be assessed per 1000 live births, as we studied prevalence of CHD cases presenting to the pediatric department.

Table 7: Prevalence of major types of Congenital Heart Disease in different countries (\%)

\begin{tabular}{|c|c|c|c|c|c|c|c|c|c|c|}
\hline Region & VSD & TOF & PDA & TGA & PS & $\mathbf{A S}$ & ASD & TAPVC & AVSD & Others \\
\hline $\mathrm{UK}^{13}$ & 32.5 & 10.9 & 11.9 & 0 & 7.6 & 5.1 & 5.9 & 0 & 2.4 & 23.7 \\
\hline $\mathbf{U S A}^{14}$ & 32 & 6.4 & 8.3 & 0 & 8.6 & 3.8 & 7.4 & 0 & 3.6 & 24.1 \\
\hline Papua $^{29}$ & 34 & 23 & 16.4 & 0 & 0 & 0 & 0 & 0 & 0 & 26.6 \\
\hline Pakistan $^{30}$ & 46 & 38 & 2.6 & 8 & 6.6 & 6.6 & 2.6 & 0 & 0 & 1.9 \\
\hline Nepal $^{31}$ & 25 & 0 & 16 & 0 & 9 & 0 & 50 & 0 & 0 & 0 \\
\hline Nigeria $^{32}$ & 35 & 0 & 22 & 10 & 9 & 0.6 & 7.5 & 0 & 0 & 15.9 \\
\hline India $^{28}$ & 46 & 10 & 14 & 0 & 4 & 4 & 18 & 0 & 0 & 4 \\
\hline Current & 29 & 26 & 5 & 9 & 1 & 1 & 13 & 4 & 1 & 11 \\
\hline
\end{tabular}

Amongst all CHDs, VSDs contributed to maximum of $29 \%$, followed by TOF $26 \%$, ASD $13 \%$, TGA $9 \%$, PDA $5 \%$, TAPVC $4 \%$, followed by complex and mixed lesions. Chada et al [28] reported CHD frequency as VSD (46\%), ASD (18\%), PDA (14\%), TOF (10\%), AS (4\%), PS (4\%). VSD was the commonest lesion, as also observed in most studies [13,14,29,30,32] except in a nepalese study by Manbahadur [31], where ASD accounted for the maximum of $50 \%$ cases. Tetralogy of Fallot was second commonest as also reported by Vashishta [3], Bidwai [23].

Amongst cyanotic lesions, Tetralogy of Fallot (26\%) comprised maximum cases, followed by Transposition of Great Arteries (9\%), Total Anomalous Pulmonary Venous connection (4\%) and others. These results were comparable with studies done by Dickinson [13], Fixler[14], Tefurani[29],Rahim[30] whereas Vashistha[9] reported TOF in $13.6 \%$ of the cases. Rarity of coarctation of aorta has been noted as by other workers [23].
The diagnosis of Congenital Heart disease is established by $1 \mathrm{wk}$ of age in 40-50\% patients, by 1 month in 50-60 $\%$ patients, $75 \%$ by 3 months and $100 \%$ by $3-4$ years of age $[2,13,33]$. We observed the mean age of presentation as 11.5 months in ACHD group, 10.5 months in $\mathrm{CCHD}<\mathrm{PBF}$ group and 5 months in $\mathrm{CCHD}>\mathrm{PBF}$ group. The mean age of diagnosis is a little later than other centres outside the country, hence early screening should be done in the form of neonatal or fetal screening for CHD. As per American College of Cardiology guidelines, there should be at least 1 pediatric cardiac programme for every 5 million people. In India, there are 14 such existing centres for an expected of 200[11]. Hence, there is a growing need of trained personnel in the field of pediatric cardiology.

CHDs were observed higher in males(59\%) as compared to females(41\%), as also observed by Chada[28] et al (4.6/1000 in boys as against 3.7/1000 in girls), whereas Tefurani [29] observed 1:1 male:female

Available online at: www.ijmrr.in 238 | P a g e 
ratio. There was female preponderance noted in VSDs as also observed by Vashishta [3], as against male preponderance in other studies[23,34]. TOF [23,34], TGA[34], ASDs[34,38] showed male preponderance as in other studies.

CHD patients are more prone to malnutrition and growth failure. Bigul Waren [35] reported that Pulmonary Hypertension appears to be the important factor, cyanotic patients with pulmonary hypertension being most severely affected, with additive effect of hypoxia. Tefurani [29] also reported 1/5 cases of CHDs had long term wasting and 1/6 cases had delayed milestones, as also observed in present study.

CHD cases had increased rate of lower respiratory tract infection. This and pulmonary arterial hypertension and pulmonary veno-occlusive disease increase perioperative morbidity and mortality [11]. The time lag between diagnosis and referral to pediatric cardiac centre results in increased rate of complications like hypoxic brain damage and eisenmenger syndrome, resulting in suboptimal utilization of resources [11].

All large studies from India have taken into consideration only one age group i.e., either newborns or school going children. The former may miss out small VSD or TOF or ductus dependant lesions, which present later after birth and can't focus on the prevalence of CHD. Other community studies on CHD prevalence include school going children (5-15 yrs); automatically exclude all the severe lesions.

Our study has certain limitations. Being a government tertiary care centre, upper class got excluded from the study. Also, stillborns who had CHD as a cause of neonatal demise and seriously ill patients who died during resuscitation (before 2D Echocardiography could be performed) could not be included in the study. We could not assess the incidence of congenital heart disease per 1000 live births in our hospital, since each child could not be screened by 2D Echocardiography and color Doppler, hence asymptomatic patients with no or subtle signs may have got missed.

Pediatric cardiac interventions have crossed the infancy and majority of the cardiac surgeries done in pediatric age are for congenital heart diseases mainly Ventricular Septal defects, ASD, TOF and PDA. Majority of the patients are diagnosed very late with substantial compromise to the cardio pulmonary functions already at presentation. This puts them to higher risk for surgery. Patient with CHD are seen by pediatricians very late and subsequent referral to cardiologists and subsequent surgery is also delayed. Also, there is a growing need of trained personnel in the field of pediatric cardiology for early diagnosis and management.

\section{Funding: Nil}

\section{Conflict of interest: Nil}

\section{Permission from IRB: Yes}

\section{References}

1. Mitchell SC, Koranes SB, Berendes HW. Congenital Heart Disease in 56109 births. Incidence Natural History. Circulation 1971; 43:323-32.

2. Ferencz C, Rubin JD, McCarter RJ, Brenner JI, Neill CA, Perry LW. Congenital Heart Disease: Prevalence at live birth. The Baltimore-Washington Infant Study. Am J Epidem 1985; 121:31-6.

3. Brassili A, Mokhtar SA, Dabous NI, Zaher SR, Mokhtar MM, Zaki A. Congenital heart disease among school children in Alexandria, Egypt: an overview on prevalence and relative frequencies. $J$ Trop Pediatr. 2000:46:357-62.

4. Kapoor R, Gupta S. Prevalence of Congenital Heart Disease, Kanpur, India. Indian Pediat 2008;45:309-11.

5. Vashishta VM, Kalra A, Kalra K, Jain VK. Prevalence of congenital heart disease. Indian Pediatr 1993; 30: 1337-40.

6. Khalil A, Aggarwal R, Thirupuram S, Arora R. Incidence of congenital heart disease among hospital live births in India. Indian Pediatr 1994; 31: 519-24.

7. Gupta J, Gupta ML, Parihar A, Gupta CD, Epidemiology of Congenital \& Rheumatic Heart Disease in School Children. J. Ind. Med. Association. 1992;90:57-9.

8. Lawn JE, Cousens S, Zupan J.4 million neonatal deaths: When? Where? Why? Lancet 2005; 365:891900 .

9. Saxena A. Congenital Heart Disease in India: A status Report. Ind. Jrnl. Paed.Vol. 72, July 2005.595-8.

10. Kinare SG, Sharma S. Congenital Heart Disease in 1st year of life (an autopsy study of 270 cases). Ind. Jrnl. Paed 1981:48:745-754. 
11. Hoffmann JIE, Samuel Kaplan. Incidence of congenital heart disease (Review article) J.Am Coll. Cardiology 2002; 39:1890-1900.

12. Warnes CA, Liberthson R, Gordon K. Danielson Jr.,Dore A, Harris L et al. Task Force 1: the changing profile of congenital heart disease in adult life. $J \mathrm{Am}$ Coll Cardiol. 2001; 37:1170-1175.

13. Dickinson DF, Arnold R, Wilkinson JL. Congenital heart disease among 160,480 live born children in Liverpool, 1960 to 1969 . Implications for surgical treatment. Br Heart J 1981; 46:55-62.

14. Fixler DE, Pastor P, Chamberlin M, Sigman E, Eifler CW. Trends in congenital heart disease in Dallas county births 1971-1984. Circulation 1990; 81:137-42.

15. Sung RY, So LY, Ng HK, Ho JK, Fok TF. Echocardiography as a tool for determining the incidence of congenital heart disease in newborn babies: a pilot study in Hong Kong. Int J Cardiol 1991; 30:43-7.

16. Meberg A, Otterstad JE, Froland G, Sorland S, Nitter-Hauges. Increasing incidence of ventricular septal disease caused by improved detection rate. Acta Paediatr 1994; 83:653-7.

17. Hassan I, Haleem AA, Bhutta ZA. Profile and risk factors for congenital heart disease. J Pak Med assoc 1997; 47:78-81.

18. Alabdulgadar AA. Congenital Heart Disease in 740 subjects, epidemiological aspects. Ann Trop Paediatr 2001; 21:111-8.

19. Mclaren MJ, Lachman AS, Barlow JB. Prevalence of Congenital Heart Disease in Black Schoolchildren of Sourno,Johhanesberg. Br Heart Jrnl, 1979, May;41(5):554-8.

20. Oloron DPM, Ibarra CR, de Aguilar VA.Incidence of Congenital Heart Disease in Navvara(1989-1998) Revista Espanola de Cardiologia 2005 Dec(58); 12:1428-34.

21. Manchandha SS, Sachdev KK. Morbidity and mortality in children in Northern India (Punjab). Indian $J$ Pediat 1962; 29:333-50.
22. Gupta S, Puri RK, Indira OC, Datta SP. Morbidity in children under 14 in South India. Indian Pediat 1968;5:485-97.

23. Bidwai PS, Mahajan CM, Walia BN, Berry JN. Congenital heart diseases in Childhood - A Clinical Study. Indian Pediatri 1971; 7:691-4.

24. Verma KC, Chabbra P, Magotra ML. A clinical study on prevalence of Heart Disease in children in Jammu \& Kashmir area. Indian Paediatr 1979; 16:597606.

25. Menache CC, du Plessis AJ, Wessel DL, Jonas RA, Newburger JW. Current incidence of acute neurologic complications after open-heart operations in children. Ann Thorac Surg 2002; 73:1752-8.

26. Khalil A. Congenital heart disease. In: Essentials of Pediatrics Cardiology, New Delhi 2003; 71-89.

27. Thakur JS, Negi PC, Ahluvalia SK, Sharma R, Bharadwaj R. Congenital Heart Disease in School children in Simla Hills. Indian Heart Journal 1995; 47:232-5.

28. Chadha SL, Singh N, Shukla DK. Epidemiological study of congenital heart disease. Indian $J$ Pediatr. 2001; 68: 507-10.

29. Tefuarani N, Hawker R, Vince J, Sleigh A, Williams G. Congenital heart disease in Papua New Guinean children. Ann Trop Paediatr. 2001; 21:285-92.

30. Rahim F, Younas M, Gandapur AJ \& Talat .A Pattern of congenital heart diseases in children at tertiary care center in Peshawar. Pak J Med Sci. 2003, 19(1)19-22.

31. ManBahadur KC, Sharma D, Shrestha MP, Gurung S, Rajbhandari S, Malla R,et al Prevalence of Rheumatic and Congenital Heart Disease in Schoolchildren of Kathmandu Valley in Nepal. Indian Heart J 2003; 55: 615-8.

32. Gupta S, Puri RK, Indira OC, Datta SP. Morbidity in children under 14 in South. Indian Pediat.1968; 5:485-497.

33. Bernstein.D. Acyanotic congenital heart disease. In. Nelson textbook of Pediatrics.18Edn. Ed: Kliegman R.M., Behrman R.E., Jenson H.B., Stanton B.F. Saunders. New Delhi.2007; 2:424:1883. 
34. Sani MU, Mukhtar-Yola, Karaye KM. Spectrum of Congenital Heart Disease in a Tropical environment: An Echocardiographic Study. Jrnl of National Med Association. 2007(June); 99:6:665-9.
35. Varan B, Tokel K, Yilmaz G. Malnutrition \& growth failure in cyanotic \& Cyanotic Heart Diseases with \& without pulmonary hypertension. Archives Dis Child 1999(July): 81: 49-52.

\section{How to cite this article?}

Hajela S. Profile of Congenital Heart Disease in childhood. Int J Med Res Rev 2014;2(3):234- 241. doi:10.17511/ijmrr. 2014.i03.7. 